\title{
Norwalk like viruses: study of an outbreak
}

\author{
Q W SPENDER, D LEWIS, AND E H PRICE \\ Departments of Child Health and Microbiology, Queen Elizabeth Hospital for Children, London
}

SUMMARY An outbreak of acute non-bacterial gastroenteritis is reported, during which a ward had to be closed, and stool samples from 15 patients showed a virus structurally similar to the Norwalk agent.

The Norwalk agent derives its name from an outbreak of acute non-bacterial gastroenteritis that occurred in Norwalk, Ohio, in 1968. ${ }^{1}$ Subsequent transmission of stool filtrates free of bacteria to adult volunteers showed that the symptoms could be reproduced ${ }^{2}$ and immune electron microscopy showed $27 \mathrm{~nm}$ particles. ${ }^{3}$ Even without antibody these particles aggregate and have a fuzzy edge, thought to represent a surface substructure, which is beyond the limit of resolution of the electron microscope to define further. Particles with a similar appearance have been called Norwalk like viruses. ${ }^{4}$ An experienced microscopist can distinguish such particles from other small round viruses seen in stool preparations: these include astrovirus, calicivirus, ${ }^{5}$ and small round featureless viruses. ${ }^{6}$ There are at least three antigenically distinct viruses in the Norwalk like group, ${ }^{7}$ and the exact serotype can be determined only by immune electron microscopy using antibody from infected individuals. Such antibody is not generally available in this country, so the agents in our study could be classified only on morphological grounds. The Norwalk like viruses are thought to be ribonucleic acid viruses of calicivirus type. ${ }^{8}$

Norwalk like viruses, in contradistinction to rotaviruses, are regarded in the United States of America as primarily pathogens of older children and adults. ${ }^{9}$ In developed countries serum antibody is acquired chiefly during adolescence, whereas in Bangladesh $100 \%$ of children have been found to acquire antibody by the age of 4 years. ${ }^{10}$ The population served by our hospital could be seen as a mixture of these two extremes. Acquisition of antibody does not protect against the disease and in fact is associated with recurrent infections by the same serotype of Norwalk virus. ${ }^{11}$ Thus infants are not likely to be protected by maternal antibody.

The illness produced by Norwalk like viruses is generally mild, lasting one to two days, with a variety of symptoms, including nausea, vomiting, diarrhoea, malaise, fatigue, headache, and low grade fever. The incubation period is generally one to two days, ${ }^{4}$ but may be up to three days. ${ }^{12}$ Transmission may be by the faeco-oral route, but may also be through vomit, which may be aerosolised, and so cause airborne transmission. ${ }^{13}$

\section{Methods}

Patients on the open ward were nursed with standard handwashing precautions between patients, while those in cubicles were nursed with the extra precautions of gloves, plastic aprons, and gowns.

Samples of stool were collected whenever a diarrhoeal illness was suspected, usually because of

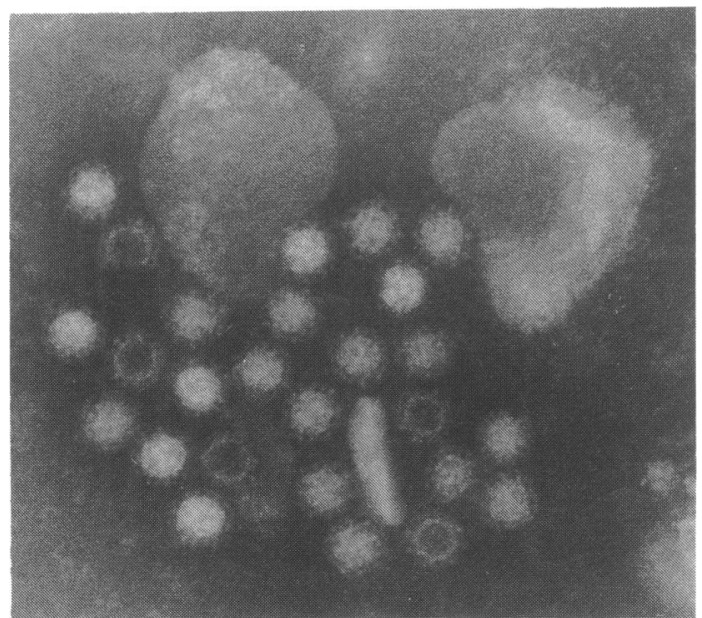

Figure Photomicrograph of small round structured viruses aggregating spontaneously in stool obtained from case 5.

Print magnification $\times 200400$ : $1 \mathrm{~mm}=4.95 \mathrm{~nm}$. 
Table 1 Temporal and spatial relations of diarrhoea, vomiting, and fever with electron microscopy visualisation of virus

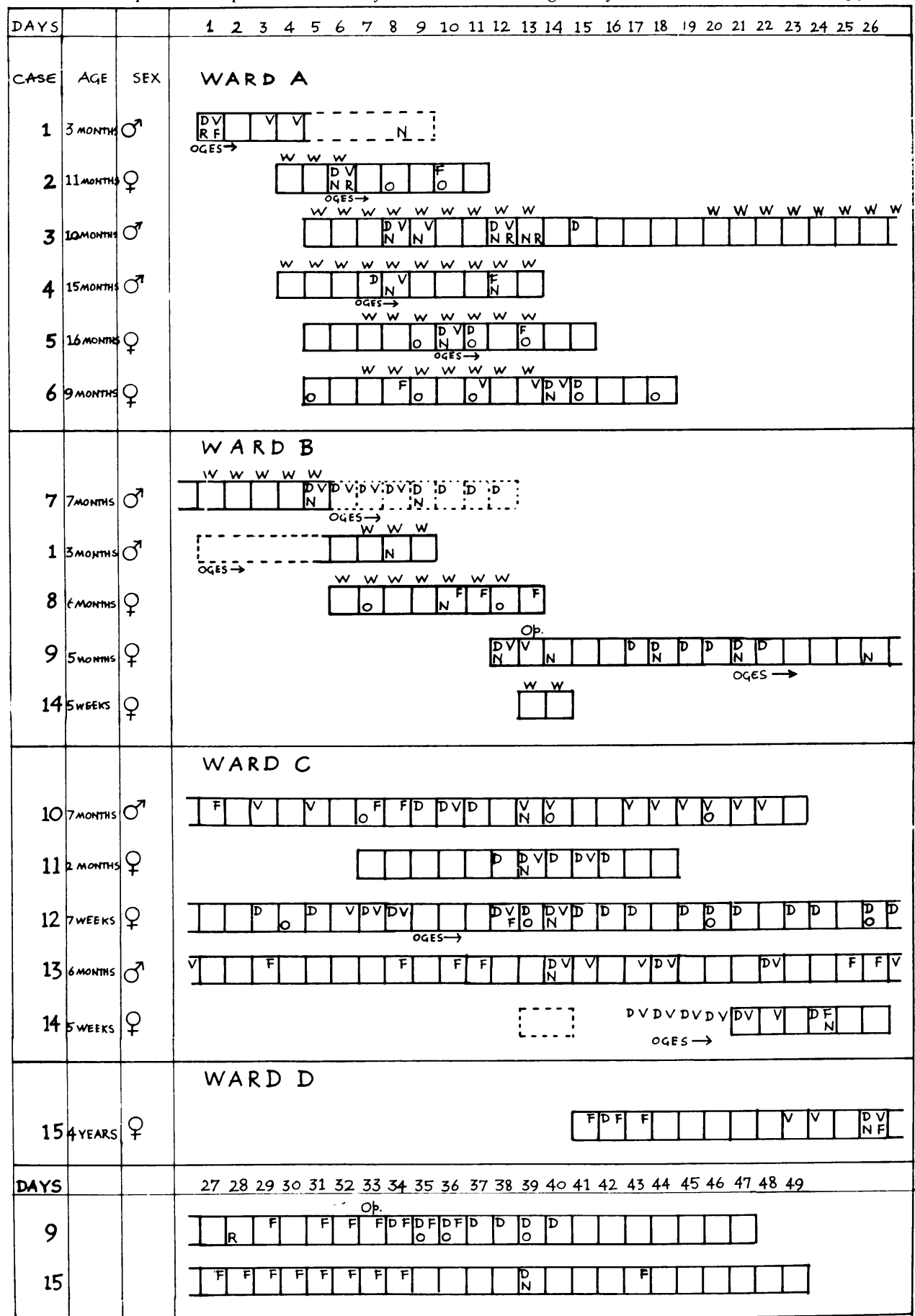

$\mathrm{D}=$ Diarrhoea, construed as a significant increase in the frequency of looseness of stools.

$\mathrm{V}=$ Vomiting (not regurgitation)

$\mathrm{F}=$ Fever of $37.5^{\circ} \mathrm{C}$ or more (axillary).

$\mathrm{W}=$ Above a box means that the patient was in the open ward for all or part of that day. Unmarked boxes indicate that the patient was nursed in a cubicle.
$\mathbf{N}=$ Small round structured viruses of Norwalk virus type seen in stool passed on this day.

$\mathbf{R}=$ Rotavirus seen in stool passed on this day

$\mathrm{O}=$ Electron microscopy of stool passed on this day disclosed no virus.

OGES=Oral glucose electrolyte solution started on this day

$\mathrm{Op}=$ Surgery under general anaesthesia on this day; nil by mouth for a time afterwards. 
Table 2 Clinical details of patients, in chronological order of occurrence of small round structured viruses in the stool. The numbering of the days refers to Table 1

Case 7-Diaphragmatic hernia repaired at birth. Admitted four days before day 1 for treatment of a chest infection on the open ward. He developed diarrhoea and vomiting on day 5 , and a stool specimen was sent on the first day of symptoms. Small round structured viruses were seen the same day, and he was transferred the following morning to the hospital's isolation ward, according to surgical ward policy. His symptoms gradually settled on treatment with oral glucose electrolyte solution: he required two regrades, and had small round structured viruses in his stool again on day 9.

Case 2-Admitted with suspected non-accidental injury to the open ward (day 4). She developed diarrhoea and vomiting on day 6 , and was put into a cubicle on the same day. She responded rapidly to oral glucose electrolyte solution despite having a dual infection.

Case 1-Pyloromyotomy and Ladd's procedure at 3 weeks of age. He was admitted on day 1 with a 24 hour history of diarrhoea and vomiting. He was febrile and drowsy. Cerebrospinal fluid, chest $x$ ray film, and blood cultures showed no infection, but rotavirus was seen in the first day's stool. He responded very rapidly to oral glucose electrolyte solution, but he then developed bile stained vomiting, and $x$ ray films showed the 'double-bubble' appearance of duodenal obstruction. He improved after being taken over by his surgical team on day 4 , with nasogastric suction and intravenous fluids, followed by gradual reintroduction of normal diet. He was transferred to the surgical ward (B) on day 5 . He did not pass a stool for four days and was therefore moved out of his cubicle before small round structured viruses were seen in the first stool he had passed (day 8 ) since his episode of obstruction. He was then rapidly discharged.

Case 3-Second admission with atopic eczema and failure to thrive. He was admitted on this occasion for topical treatment and a diet of 'Nutramigen' only. He seemed to develop two distinct episodes of symptomatic infection, the first single and the second dual. Neither made him ill, but they both interfered with his weight gain.

Case 4-Admitted for investigation of failure to thrive, which was found to be due to housing problems.

Case 5-Cows' milk protein intolerance. She was admitted for a jejunal biopsy, to be followed by lactose challenge and then milk challenge. The lactose challenge had to be abandoned because of symptoms related to brief carriage of Norwalk like virus.

Case 8-Congenital anorectal atresia and renal anomalies. The former had been treated by colostomy, which made it impossible to judge from the nursing records whether she had had diarrhoea. She had had meningitis aged 3 weeks, with hydrocephalus and seizures as sequelae. She was admitted on this occasion for control of fits. Samples were sent because of her proximity to case 7 . She had a mild febrile illness associated with brief passage of small round structured viruses.

Case 9-Spina bifida and hydrocephalus, treated surgically soon after birth. She was transferred from her local hospital because of a cerebrospinal fluid leak, and was noted before transfer to be passing loose stools, so was put straight into a cubicle. Her admission (day 12) specimen contained small round structured viruses, as did subsequent specimens up to day 26 . There was little correlation between viral carriage and symptoms noted at the time but she did have a prolonged period of diarrhoea, attributable to the viruses, which settled on treatment with oral glucose electrolyte solution started on day 21 . She subsequently developed rotavirus Her initial vomiting was thought possibly to be due to raised intracranial pressure, and a prolonged fever was attributed to problems with her shunt. A second period of diarrhoea could not be associated with a virus. Her medical problems do not provide an explanation for the apparently prolonged carriage of Norwalk like viruses-but these may have comprised more than one strain.

Case 10-Admitted 44 days before day 1 . He had subtotal villous atrophy of uncertain cause, which responded to treatment with 'Alfaré formula feed; pelviureteric junction obstruction; and transient abnormalities of $\mathrm{T}$ cell function. His immunity was normal at the time of this infection. His symptoms show no clear relation to carriage of small round structured viruses.

Case 11-Bronchiolitis. She had a brief episode of gastroenteritis clearly associated with carriage of small round structured viruses, but not severe enough to require treatment with oral glucose electrolyte solution.

Case 6-Failure to thrive. On admission to the ward (day 5) she was put in the cubicle vacated by case 1 . On day 7 she was moved out of a cubicle and was put back in when the ward was reopened on day 13. Only one of a number of stools was seen to have small round structured viruses, and she had mild symptoms over an eight day period, at least some of which could be attributed to this.

Case 12-Admitted eight days before day 1, with pertussis. She had frequent episodes of vomiting with coughing spasms, so ' $\mathrm{V}$ ' was entered in Table 1 only if this seemed to be more than usual. She also seemed to have frequent loose stools, which settled on the one occasion when oral glucose electrolyte solution was given, but did not bear a very clear relation to carriage of virus (she was discharged on day 29).

Case 13-Panhypopituitarism due to congenital toxoplasmosis. He was admitted with hypernatraemia nine days before day 1; some of his vomiting may have been related to electrolyte or cortisol imbalance. He did, however, have mild diarrhoea and vomiting associated with carriage of small round structured viruses, and this may possibly have contributed to problems adjusting the dosage of his replacement hormones (he was discharged on day 47).

Case 14-Elective hernia repair on ward B. She developed gastroenteritis three days after discharge and was treated as an outpatient in casualty because of a shortage of cubicles. After a poor response to treatment with oral glucose electrolyte solution, she was admitted to ward $\mathrm{C}$, where her symptoms settled.

Case 15-T cell acute lymphoblastic leukaemia. She was receiving intensive induction chemotherapy. A prolonged fever was thoroughly investigated, and the only identifiable cause found was a Norwalk like virus, whose stool carriage seemed also to be prolonged. Her neutrophil count was negligible until day 34 , and did not begin to approach safe levels until day 45-much later than envisaged in the treatment protocol, which therefore had to be adjusted. This was blamed at the time on the virus.

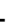
.

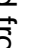


one or more loose stools, as a follow up on patients already found to be excreting Norwalk like virus, and on some contacts of infected patients. The samples were sent for light microscopy, bacterial culture, and electron microscopy (performed by DL), according to ward policy, with the follow up and contact specimens being sent for electron microscopy only. Stool was not routinely cultured for viruses (Norwalk like viruses cannot be isolated in viral culture at present). Specimens of vomit were not, unfortunately, sent for electron microscopy.

Stools were prepared as $30 \%$ suspensions in distilled water and examined by a direct electron microscopy method. ${ }^{14}$ Some were stored at $-20^{\circ} \mathrm{C}$ before examination. All the viral particles observed from the outbreak and classified as small round structured viruses of Norwalk type had a similar morphology, with an indistinct substructure, a fuzzy edge, and an approximate diameter of $30 \mathrm{~nm}$ (Figure).

\section{Results}

Table 1 shows the temporal and spatial relations of diarrhoea, vomiting, and fever with electron microscopy visualisation of virus. Each box represents a day during admission. The 15 patients were those found to have Norwalk like virus in stool specimens sent during a 26 day period. This period was chosen to include all possible links to the apparent outbreak. No other patients in the hospital were known to have small round structured viruses during these 26 days. The key explains the symbols used. Ward B is a surgical ward, the others medical. Potentially relevant details were extracted retrospectively from routine medical notes and nursing charts. Table 1 shows also when patients were in cubicles and when on the open ward. Two of the patients had apparently prolonged carriage and so are the subjects of a continuation of the Table beyond the arbitrary day 26.

Table 2 gives the reasons for admission and additional clinical details of the patients.

No child became significantly dehydrated in association with small round structured viruses. Nine children were treated with oral glucose electrolyte solution, and only case 1 required additional treatment for gastroenteritis. $\mathrm{He}$ required intravenous fluids at the time of rotavirus excretion, and again at the time of duodenal obstruction, which was interpreted as a complication of his previous surgery, albeit in retrospect associated with infection by Norwalk like virus. Patient 15 required intravenous fluids as part of her chemotherapy for leukaemia.

Ward A had the most pronounced spatial and temporal clustering of cases. Several nurses, the ward teacher, and a physiotherapist also became ill. No doctor admitted to having relevant symptoms. Samples were unfortunately not received from any of these adults. On all specimens sent bacterial cultures were negative for salmonella, shigella, enteropathogenic Escherichia coli, campylobacter, and aeromonas species, as was light microscopy for ova, cysts, and parasites, including cryptosporidia.

When it became clear, on day 8 , that the number of free cubicles in the hospital would not be sufficient for the number of patients with loose stools, ward A was closed to admissions, and treated as one large cubicle. Patients were sent home when possible, or regarded as non-infectious when at least one stool specimen had no small round structured viruses on electron microscopy. When the number of patients giving rise to doubt had been sufficiently reduced (day 13) these were transferred to individual cubicles, and the ward was reopened.

The clinical picture of disease attributable to Norwalk like virus in this study is generally mild. In most children, it caused a brief episode of gastroenteritis; in a few of these the purpose of admission was compromised (cases 3, 4, 5, and 6). In some with pre-existent disease it seemed to contribute to complications (case 1). Combined virus infections including Norwalk like virus have been reported to cause more severe symptoms than Norwalk like virus alone ${ }^{15}$ and this may have contributed to the clinical picture in case 1 , but seems to be of no relevance to cases 2,3 , or 9 .

Because of the method of ascertainment of cases there is clearly a bias towards the correlation of gut symptoms with carriage of small round structured viruses. The relation is nevertheless tenuous in some cases (cases 8, 9, 10, and 12), suggesting that asymptomatic infection may occur more commonly than we have been able to show.

\section{Discussion}

Because the data are retrospective many unanswered questions remain. The initial impression of an 'outbreak' came not only from the number of patients with symptoms of gastroenteritis on the ward at once, but also from the number of staff who became ill.

Even when a stool sample is sent at the time of peak excretion of virus, electron microscopy is almost certainly not as sensitive at detecting small round structured viruses as at diagnosing rotavirus infection. Allowing in addition for incomplete sending of samples, there must have been significant under ascertainment.

Identification of the pattern of spread is made 
highly speculative by the numerous possible modes of transmission. Asymptomatic carriage enables faeco-oral transmission to take strange routes. Aerosol inhalation seems to occur, ${ }^{13}$ and adult staff may, as with other viral infections, transfer the virus in respiratory droplets. The virus must have quite a high prevalence in the community to account for cases occurring in our hospital all the year round. Visiting adults and children may therefore transmit the organism to inpatients. Also contamination of surfaces is possible in spite of routine cleaning and disinfection procedures and may have been a further source of infection.

We had no way of distinguishing serotypes: two or more $^{7}$ may have been involved, and the patients with apparently prolonged carriage (cases 9 and 15) may actually have been reinfected with a different strain, as has been described with rotavirus. ${ }^{16}$

As no overlap in medical or nursing staff could be found between cases 7 and 2, nor any proximity of address, it was considered that case 1 must be the link between wards $A$ and $B$, which was why he was put first in Table 1 . He shared surgical staff with case 7 , even before he moved wards, which might explain a transmission, through vomit, that would otherwise be backwards in time. There are, of course, alternative explanations for the simultaneous occurrence of cases on the two wards: it might even have been coincidence.

Case 2 developed a dual infection after two asymptomatic days on the ward. Although she was possibly incubating both the infections during these two days, the evidence seems more in favour of the hypothesis that she acquired them from case 1 , despite his being in a cubicle at the time.

The subsequent cases on ward $A$ are unlikely to have been coincidental, although case 9 on ward B probably was.

The four patients in cubicles on ward $\mathrm{C}$ in whom small round structured viruses were detected within a two day period are very suggestive of a common source. This was thought at the time to be the house physician involved directly with the care of cases 6 , 10 , and 11 , and indirectly with the care of cases 5 , 12 , and 13 . He apparently had no symptoms.

Infection with Norwalk like virus was originally thought to be a winter disease ${ }^{1}$ but outbreaks have occurred at all times of year. ${ }^{8}$ In a previous study at this hospital the peak incidence of Norwalk like infections-presumably acquired in the community, at least principally-was in March, April, and May. ${ }^{15}$ The collection of cases we report here occurred at the end of January and during February (day $8=1$ February).

Outbreaks of infection with Norwalk like viruses are common world wide. A review of 24 such outbreaks includes five common source epidemics, due to contaminated water or food, and 17 episodes in institutionalised communities. ${ }^{8} \mathrm{~A}$ minority of the latter type have occurred in hospitals, including a psychogeriatric unit, ${ }^{12}$ a maternity unit, ${ }^{17}$ and a children's asthma research institute. ${ }^{18}$ Patient to patient spread was shown to be associated with symptomatic excretion by nursing and medical staff. $^{12} 18$

\section{Conclusion}

Nosocomial infection with Norwalk like viruses may well be commoner than is generally realised. With the benefit of electron microscopy identification on morphological grounds, we have shown that significant spread of infection, albeit causing a generally mild illness, seems to occur in spite of standard nursing procedures and even isolation precautions.

We thank Professor J A Walker-Smith for helpful advice and $\mathrm{Mr}$ $\mathrm{J}$ H Spender for the typography of Table 1.

\section{References}

1 Adler JL, Zickl R. Winter vomiting disease. J Infect Dis 1969;119:668-73.

2 Dolin R. Blacklow NR. DuPont H. et al. Transmission of acute nonbacterial gastroenteritis to volunteers by oral administration of stool filtrates. J Infect Dis 1971;123:307-12.

${ }^{3}$ Kapikian AZ, Wyatt RG, Dolin R, Thornhill TS, Kalica AR, Chanock RM. Visualization by immune electron microscopy of a $27 \mathrm{~nm}$ particle associated with acute infectious non-bacterial gastroenteritis. J Virol 1972;10:1075-81.

4 Blacklow NR, Cukor G. Viral gastroenteritis. N Engl J Med 1981;304:397-406.

5 Madeley CR. Comparison of the features of astroviruses and calciviruses seen in samples of feces by electron microscopy. J Infect Dis 1979;139:519-23.

${ }^{6}$ Caul EO, Appleton H. The electron microscopical and physical characteristics of small round human fecal viruses: an interim scheme for classification. J Med Virol 1982;9:257-65.

7 Kapikian AZ, Yolken RH, Greenberg HB, et al. Gastroenteritis viruses. In: Lennette EH, Schmidt NJ, eds. Diagnostic procedures for viral, rickettsial and chlamydial infections. Washington, DC: American Public Health Association, 1978:927-95.

${ }^{*}$ Greenberg HB, Wyatt RG, Kalica AR, et al. New insights in viral gastroenteritis. In: Pollard $\mathrm{M}$, ed. Perspectives in virology. Vol XI. New York: Raven Press, 1981:163-87.

${ }^{9}$ Cukor G, Blacklow NR. Human viral gastroenteritis. Microbiol Rev 1984;48:157-79.

${ }^{10}$ Black RE, Greenberg HB, Kapikian AZ, Brown KH, Becker S Acquisition of serum antibody to Norwalk virus and rotavirus and relation to diarrhea in a longitudinal study of young children in rural Bangladesh. $J$ Infect Dis 1982;145:483-9.

" Parrino TA, Schreiber DS, Trier JS, Kapikian AZ, Blacklow NR. Clinical immunity in acute gastroenteritis caused by Norwalk agent. $N$ Engl J Med 1977;297:86-9.

12 Gustafson TL, Kobylik B, Hutcheson RH, Schaffner W. Protective effect of anticholinergic drugs and psyllium in a nosocomial outbreak of Norwalk gastroenteritis. J Hosp Infect $1983 ; 4: 367-74$. 
${ }^{13}$ Greenberg HB. Wyatt RG, Kapikian AZ. Norwalk virus in vomitus. Lancet 1979;i:55.

${ }^{14}$ Rice SJ, Phillips AD. Rapid preparation of faecal specimens for detection of viral particles by electron microscopy. Med Lab Sci 1980;37:371-2.

15 Storr J, Phillips AD, Rice SJ, Walker-Smith JA. The Norwalk agent. J Pediatr Gastroenterol Nutr 1986; (In Press).

16 Yolken RH, Wyatt RG, Zissis GP, et al. Epidemiology of human rotavirus types 1 and 2 as studied by enzyme-linked immunosorbent assay. $N$ Engl J Med 1978;299:1156-61.
17 Appleton H. Higgins PG. Viruses and gastroenteritis in infants. Lancet 1975;:i:1297.

ix Judson FN, Molk L. Epidemic acute infectious non-bacterial gastroenteritis at the children's asthma research institute and hospital. Am J Epidemiol 1975:102:251-6.

Corespondence to Dr Q W Spender, Hospital for Sick Children, Great Ormond Street, London WC1N 3JH.

Received 2 October 1985

\section{British Paediatric Association}

Annual meetings

1986 15-19 April York University

1987 7-11 April York University

1988 12-16 April York University 